\title{
Overcoming the unitary exploration of binge-watching: A cluster analytical approach
}

\author{
MAÈVA FLAYELLE ${ }^{1}$, PIERRE MAURAGE ${ }^{2}$, LAURENT KARILA $^{3}$, CLAUS VÖGELE $^{4}$ and JOËL BILLIEUX ${ }^{1,5 *}$ \\ ${ }^{1}$ Addictive and Compulsive Behaviours Lab (ACB-Lab), Institute for Health and Behaviour, University of Luxembourg, \\ Esch-sur-Alzette, Luxembourg \\ ${ }^{2}$ Laboratory for Experimental Psychopathology (LEP), Psychological Sciences Research Institute, Université catholique de Louvain, \\ Louvain-la-Neuve, Belgium \\ ${ }^{3}$ Hôpital Universitaire Paul Brousse, Service d'addictologie, Université Paris Saclay, Equipe d'Accueil Université Paris Sud PSYCOMADD, \\ Villejuif, France \\ ${ }^{4}$ Clinical Psychophysiology Laboratory (CLIPSLAB), Institute for Health and Behaviour, University of Luxembourg, \\ Esch-sur-Alzette, Luxembourg \\ ${ }^{5}$ Institute of Psychology, University of Lausanne, Lausanne, Switzerland
}

(Received: July 12, 2019; revised manuscript received: August 26, 2019; accepted: August 28, 2019)

\begin{abstract}
Background and aims: Binge-watching (i.e., watching multiple episodes of a TV series in one session) has recently become standard practice among TV series viewers; this expansion generates concerns regarding the potential negative outcomes associated with this habit. However, the investigation of its psychological correlates remains fragmentary, with few initial studies a priori conceptualizing this behavior as a new addictive disorder. This study explored these psychological correlates using cluster analysis of binge-watching behavior based on three key psychological factors: motivations, impulsivity, and emotional reactivity. Methods: An online survey was completed by 4,039 TV series viewers. Data were analyzed using hierarchical and non-hierarchical cluster analyses, the validity of the clusters being finally determined through mutual comparisons with a selection of external correlates. Results: Four clusters were identified: recreational TV series viewers (presenting low involvement in binge-watching), regulated binge-watchers (moderately involved), avid binge-watchers (presenting elevated but non-problematic involvement), and unregulated binge-watchers (presenting potentially problematic involvement associated with negative outcomes). Discussion and conclusions: This study underlines the heterogeneous and multidetermined nature of binge-watching. Our findings suggest that high engagement in binge-watching is distinct from problematic binge-watching, thus reinforcing the notion that conceptualizing binge-watching as an addictive disorder is of low relevance and might actually lead to the overpathologization of this highly popular leisure activity.
\end{abstract}

Keywords: binge-watching, TV series, addictive behaviors, cluster analysis, behavioral addictions, impulsivity

\section{INTRODUCTION}

Methods and pace of TV series watching have undergone major changes within the new digital era and its sophisticated technological innovations. By removing the constraints of time and place, on-demand viewing and online streaming services (e.g., Netflix, Amazon, Disney, Fox, Hulu, when only confining to legal downloading platforms) have achieved tremendous popularity over recent years (the most famous of these henceforth counts 151 million members in over 190 countries; Netflix Media Center, 2019). These services are now granting TV series viewers unlimited access to a prolific catalog of programs that they can watch all in one sitting on nearly any kind of Internet-connected device. In this context, binge-watching (broadly defined as consecutively watching multiple episodes of TV series) has rapidly become standard practice among the community of viewers, the majority of who report this as their favored means of consuming TV entertainment (YouGov Omnibus, 2017).
In addition to its massive growth in popularity, binge-watching has also been in the focus of recent research where concerns are increasingly expressed about the potential adverse outcomes that may arise from excessive binge-watching. There is growing evidence that prolonged involvement in binge-watching may become problematic and engender damaging consequences for viewers (e.g., lack of sleep, decreases in exercise and healthy eating, less

\footnotetext{
* Corresponding authors: Maèva Flayelle; Addictive and Compulsive Behaviours Lab (ACB-Lab), Institute for Health and Behaviour, Université du Luxembourg, Maison des Sciences Humaines, 11, Porte des Sciences, L-4366, Esch-sur-Alzette, Luxembourg; Phone: +352 466644 5332; Fax: +352 466644 39207; E-mail: maeva. flayelle@uni.lu; Joël Billieux; Addictive and Compulsive Behaviours Lab (ACB-Lab), Institute for Health and Behaviour, Université du Luxembourg, Maison des Sciences Humaines, 11, Porte des Sciences, L-4366, Esch-sur-Alzette, Luxembourg; Phone: +352 466644 9207; Fax: +352 466644 39207; E-mail: joel.billieux@uni.lu
}

This is an open-access article distributed under the terms of the Creative Commons Attribution-NonCommercial 4.0 International License, which permits unrestricted use, distribution, and reproduction in any medium for non-commercial purposes, provided the original author and source are credited, a link to the CC License is provided, and changes - if any - are indicated. 
effective day-to-day functioning, and reduced social life; Exelmans \& Van den Bulck, 2017; Hernández Pérez \& Martínez Díaz, 2016; Rubenking, Bracken, Sandoval, \& Rister, 2018; Vaterlaus, Spruance, Frantz, \& Kruger, 2018). As a behavior obviously involving a self-control dilemma (i.e., succumbing or not to the vivid desire to watch "just one more" episode) as well as potential dysregulation implying negative consequences, a growing body of research have, therefore, emerged in parallel to investigate the potential addictive nature of binge-watching (e.g., Granow, Reinecke, \& Ziegele, 2018; Orosz, Bőthe, \& Tóth-Király, 2016; Riddle, Peebles, Davis, Xu, \& Schroeder, 2017; Shim, Lim, Jung, \& Shin, 2018; Starosta, Izydorczyk, \& Lizińczyk, 2019).

Nevertheless, most of the studies conducted so far have conceptualized binge-watching as a unitary construct, solely characterized in quantitative terms (i.e., on the basis of variable criteria of intensity such as quantity of episodes seen or hours spent viewing), while preliminary qualitative findings suggest that it is an heterogeneous and multidetermined phenomenon (Flayelle, Maurage, \& Billieux, 2017), potentially involving different binge-watchers' subprofiles (Shim et al., 2018).

In such a context, little is known about the psychological processes involved in binge-watching, thus hampering a genuine understanding of what specifically drives this behavior, as well as of how and under what circumstances it may become problematic. This is especially true as the majority of previous studies is characterized by an a priori conceptualization of binge-watching as a genuine addictive disorder, focusing on the identification of apparent symptomatic similarities with established behavioral addictions, thereby neglecting more in-depth explorations of its underlying psychological mechanisms. All this is part of a more general trend within the addiction research field where excessive-like recreational and rewarding behaviors are most often dealt with from such a "confirmatory" approach, which is increasingly criticized (Billieux, Schimmenti, Khazaal, Maurage, \& Heeren, 2015; Kardefelt-Winther et al., 2017; Starcevic, Billieux, \& Schimmenti, 2018). In addition to being simplistic, such an approach is likely to result in the overpathologization of common behaviors and to hamper both conceptualization and clinical interventions related to these problematic behaviors (Billieux, Schimmenti, et al., 2015; Kardefelt-Winther et al., 2017). To advance bingewatching research beyond these conceptual limitations, it is mandatory to distinguish between elevated (but safe) and problematic binge-watching (Flayelle, Canale, et al., 2019; Tóth-Király, Böthe, Tóth-Fáber, Gyözö, \& Orosz, 2017), adopting a psychological processes-oriented approach which is liable to provide a more complete understanding of one's media use and media-related behaviors (Billieux, Philippot, et al., 2015; van Koningsbruggen, Hartmann, \& Du, 2017).

Media use, however, is the complex result of an intertwined set of factors (Dill, 2013; Valkenburg, Peter, \& Walther, 2016), thus making it difficult to determine which types of psychological factors are involved in the reasons why certain TV series viewers give in to binge-watching, sometimes to an excessive or problematic extent. In this context, the Differential Susceptibility to Media Effects
Model (Valkenburg \& Peter, 2013) is of particular relevance. Grounded in the media effects literature, this integrative model posits that there are strong individual differences in susceptibility to media effects. Its primary assumption is that, not only being transactional, media effects are first and foremost conditional as that they are contingent upon specific dispositions of media users. "Dispositional susceptibility" is defined in this paradigm as all person dimensions that predispose the selection of and responsiveness to media (Valkenburg \& Peter, 2013, p. 226), including individual motivations and personality traits. A second assumption is that media effects are indirect, given that certain "media response states" (i.e., originating from media use) mediate the relationship between media use and media effects. Among these, an "emotional response state," which encompasses all affective reactions to media content, and an "excitative response state," referring to the degree of physiological arousal in response to media, interactively make up the notable emotional processing that occurs during and shortly after exposure, and which acts as a mediator.

Capitalizing on these theoretical benchmarks, we propose that (a) motivations, (b) impulsivity traits, and (c) emotional reactivity are key psychological factors that interact with "addictive" qualities of TV series (which notably lie in narrative tactics and genres specificities), thus making individuals more or less prone to binge-watching. In the following, we outline their individual relevance in distinguishing high (but safe) from problematic binge-watching.

\section{Potential key psychological factors related to binge-watching}

Underlying motivations of TV series watching are crucial indicators to consider when it comes to binge-watching development and maintenance. Individual motives for media use are known to play a pivotal role as regards to the comprehension of media effects in most prominent media theories such as Uses-and-Gratifications (Katz, Blumler, \& Gurevitch, 1973; Rubin, 2009) and Selective Exposure (Knobloch-Westerwick, 2015; Zillmann \& Bryant, 1985) approaches. Whether complementary or compensatory, media users typically select media content in response to their needs or desires among a wide array of media options that provide numerous immediate gratifications. As for bingewatching, a variety of motivations (e.g., social interaction, hedonism, relaxation, escape from reality, and selfdevelopment) have already been emphasized (Flayelle et al., 2017; Panda \& Pandey, 2017; Pittman \& Sheehan, 2015; Sung, Kang, \& Wee, 2018). Nevertheless, the extent to which each of these drivers differently accounts for the onset and perpetuation of binge-watching, whether problematic or not, remains largely unknown. This is a right way forward for research to consider, though, as preliminary findings indicate associations between harmonious passion for TV series watching and specific forms of motivations (i.e., social interaction and self-development; Tóth-Király et al., 2017). Conversely, based on the literature on excessive and addictive behaviors, several additional motives can be suspected to contribute to problematic forms of bingewatching. A prime example is escapism, which may result in 
dysfunctional coping (e.g., stress reduction), and whose influence on the emergence (and maintenance) of a wide range of problem behaviors is a well-acknowledged fact (e.g., Internet overuse and immoderate involvement in online video gaming or gambling; Canale, Vieno, Griffiths, Rubaltelli, \& Santinello, 2015; Kardefelt-Winther, 2014; Yee, 2007).

As selective exposure and responsiveness to the media are not only guided by the goals but also by the personality of media users (Valkenburg \& Peter, 2013), the investigation of the role of impulsivity, or self-control-related traits, in binge consumption of TV series episodes makes sense. In line with this approach, it is noteworthy that the pervasive access to media options is increasingly posited as a challenge to users' self-control abilities (Hofmann, Reinecke, \& Meier, 2017; Schnauber-Stockmann, Meier, \& Reinecke, 2018). Previous research has shown associations between media users' trait impulsivity and their media use (Minear, Brasher, McCurdy, Lewis, \& Younggren, 2013; Panek, 2014), suggesting that (a) giving in to media desires is among the most prevalent forms of self-control failure in everyday life (Hofmann, Vohs, \& Baumeister, 2012; Reinecke \& Hofmann, 2016), and that (b) self-control is a possible moderator of media use effects (Hofmann et al., 2017). The research focus on self-control seems legitimate, given that TV series viewers frequently watch longer than they intend (De Feijter, Khan, \& Van Gisbergen, 2016; Flayelle et al., 2017; Riddle et al., 2017), thus leading some authors to suggest that streaming services should enable viewers to preselect their maximum viewing duration before beginning each screening session for regulation purposes (Alter, 2017; Exelmans \& Van den Bulck, 2017). Other preliminary findings further reported that self-control deficiency fosters binge-watching (Hasan, Kumar Jha, \& Liu, 2018; Tukachinsky \& Eyal, 2018), which is associated with heightened impulsivity (Riddle et al., 2017). Nevertheless, this latter study tackled impulsivity from a unidimensional perspective, while a multifaceted conceptualization of the construct would be far better suited. It is indeed well established that impulsivity, which is a transdiagnostic factor involved in a variety of mental disorders (for a metaanalysis, see Berg, Latzman, Bliwise, \& Lilienfeld, 2015), encompasses a combination of distinct facets underpinned by specific psychological mechanisms (Dawe \& Loxton, 2004; Enticott \& Ogloff, 2006; Smith et al., 2007). According to one of the most influential models in the field, i.e., the UPPS model of impulsivity (Cyders \& Smith, 2008; Whiteside \& Lynam, 2001), impulsivity includes five main dimensions: negative urgency (the tendency to act rashly when experiencing intense negative emotions), positive urgency (the tendency to act rashly when experiencing intense positive emotions), lack of premeditation (the tendency not to take into account the consequences of an act before engaging in that act), lack of perseverance (the tendency to have difficulty remaining focused on a boring and/or difficult task), and sensation seeking (the tendency to enjoy and pursue new and exciting activities). This multidimensionality of impulsivity is all the more worth considering when exploring binge-watching, as previous studies have highlighted specific links between each of these subcomponents and several addictive behaviors (e.g., excessive
Internet use, alcohol and drug abuse, and gambling disorder; for a review, see Rochat, Billieux, Gagnon, \& Van der Linden, 2018). Drawing from previous work that conceptualized problematic binge-watching as a maladaptive emotion regulation strategy (Flayelle, Maurage, Vögele, Karila, \& Billieux, 2019), emotion laden impulsivity, which is a strong predictor of maladaptive behaviors serving to regulate affective states through the relief of negative emotions (Anestis, Selby, \& Joiner, 2007; Billieux, Gay, Rochat, \& Van der Linden, 2010; Selby, Anestis, \& Joiner, 2008), may, for example, account for the distinctiveness of problem binge-watching.

Finally, as one of the major variables through which the effects of TV series watching arise, emotional reactivity could constitute a third key factor in binge-watching behaviors. Emotions have been demonstrated to be at the heart of the dynamics underlying media use and its effects (Konijn, 2012; Nabi, 2009; Wirth, 2006), and involvement in TV series watching, in particular, has been conceptualized as the emotional response to the storyline of a show (Greenberg, Neuendorf, Rothfuss, \& Henderson, 1982). This is in line with the core principles of screenwriting, according to which it is only through emotional impact that effective storytelling engages viewers (Field, 2005; Iglesias, 2005; McKee, 2010). This ultimately implies that individual differences in emotional reactivity must come into play as regards to the extent of binge-watching commitment and presumably also its excessive or problematic counterpart. In fact, high emotional reactivity is a hallmark of psychopathology, and it is worth stressing that previous studies found positive associations between high emotional reactivity, reduced executive/ inhibitory control, and problematic behaviors (e.g., Nock, Wedig, Holmberg, \& Hooley, 2008; Pessoa, 2009; Silk, Steinberg, \& Morris, 2003).

The aim of this study was, therefore, to explore bingewatchers' psychological characteristics by identifying potential subgroups of TV series viewers, taking into account the combination of motivations for TV series watching, impulsivity traits, and emotional reactivity, and, ultimately, to clarify whether certain subgroups of viewers are more susceptible to problematic binge-watching. To this end, we used cluster analysis on data from a large sample of TV series viewers, where affect (as an indirect measure of comorbid psychopathology) and co-occurring problematic (non-substance- and substance-related) behaviors were part of the external correlates being investigated.

\section{METHODS}

\section{Procedure}

An online survey was distributed to French-speaking TV series viewers who were members of active TV shows' fan communities on Facebook and online discussion boards in November and December 2016. To capture the diversity of binge-watching habits, the inclusion criteria described in the invitation to take part in the survey were non-restrictive, i.e., being of legal age and having watched TV series episodes on a regular basis on DVD, USB, SVOD, or streaming devices, over the past 6 months. 


\section{Participants}

The survey recorded a rate of $48.51 \%$ of full responses among the 8,326 participants who started to answer questionnaires, thus constituting a sample of 4,039 cases (not differing from the global one in terms of age and gender), which was included in statistical analyses. Most of final sample were female $(80.34 \%)$ and ages ranged from 18 to 69 years old $(M=24.90, S D=7.57)$. With regard to their professional status, participants reported to be students (57.76\%), employed (35.39\%), unemployed $(6.46 \%)$, or retired $(0.39 \%)$.

\section{Measures}

The online survey was designed to assess the following clustering variables: (a) TV series-watching motivations, (b) impulsivity traits, and (c) emotional reactivity as well as the following external correlates: (a) sociodemographic characteristics, (b) TV series-watching patterns, (c) bingewatching engagement and symptoms of problematic bingewatching, (d) affect, (e) problematic Internet use, and (f) alcohol-related problems.

The sociodemographic variables assessed included age, gender, educational level, and marital status. A series of items (see Appendix) were used to rate TV series-watching behaviors by evaluating the frequency of viewing and its intensity, by asking for the average time spent watching during a typical screening session, the number of episodes usually watched consecutively, and the number of TV series generally followed at the same time. Additional items were employed to measure both self-perceived dependency (the use of the term "dependency" throughout this manuscript is to be understood as psychological dependency) on TV series, the extent to which participants considered their consumption of TV series as problematic, and whether or not they planned to modify their current viewing behavior. Finally, participants were shown a list of TV series genres (e.g., comedy, drama, detective) and asked to select which of them they most frequently watch or generally prefer.

The questionnaires included in the online survey have all been validated with French-speaking samples. Table 1 describes the scales used and reports their internal reliability. TV series-watching motivations were evaluated with the French Watching TV Series Motives Questionnaire (WTSMQ; Flayelle, Canale, et al., 2019), a 22-item scale measuring four core motivational aspects related to TV series watching: social, emotional enhancement, enrichment, and coping/escapism. Items are scored on a 4-point Likert scale ranging from 1 (not at all) to 4 (to a great extent), with higher scores indicating higher motivational levels. The degree of binge-watching commitment and problematic binge-watching was also assessed using the French Binge-Watching Engagement and Symptoms Questionnaire (BWESQ; Flayelle, Canale, et al., 2019), a 40-item scale measuring engagement in binge-watching (i.e., engagement, positive emotions, desire/savoring, and pleasure preservation) and symptoms of problematic bingewatching (i.e., binge-watching, dependency, and loss of control). Items are scored on a 4-point Likert scale ranging from 1 (strongly disagree) to 4 (strongly agree), with higher scores representing higher involvement in binge-watching and problematic binge-watching. Impulsivity traits were evaluated with the French Short UPPS-P Impulsive Behavior Scale (Billieux et al., 2012), a 20-item scale measuring five facets of impulsivity: positive urgency, negative urgency, lack of premeditation, lack of perseverance, and sensation seeking. Items are scored on a 4-point Likert scale ranging from 1 (strongly agree) to 4 (strongly disagree). Some items are reversed, so that higher scores indicate higher levels of impulsivity traits. Emotional reactivity was rated with the French version of the Emotion Reactivity Scale (Lannoy et al., 2014; original English version: Nock et al., 2008), a 21-item scale allowing for the calculation of a global emotional reactivity score. Items are scored on a 5point scale ranging from 0 (not at all like me) to 4 (completely like me), with a higher score signifying higher emotional reactivity. Affect was measured with the French Positive and Negative Affect Schedule (PANAS; Gaudreau, Sanchez, \& Blondin, 2006; original English version: Watson, Clark, \& Tellegen, 1988), a 20-item scale evaluating positive and negative affect as experienced in general. Items are scored on a 5-point scale ranging from 1 (very slightly or not at all) to 5 (very $m u c h$ ), with higher scores representing more prevalent emotional experiences. Finally, we assessed both problematic Internet use and alcohol abuse. Problematic Internet use was measured with the French Compulsive Internet Use Scale (CIUS; Khazaal et al., 2012; original English version: Meerkerk, Van Den Eijnden, Vermulst, \& Garretsen, 2009), a 14-item scale rating core features of Internet addictive use: loss of control, preoccupation, withdrawal symptoms, coping or mood modification, and conflict. Items are scored on a 5-point scale ranging from 0 (never) to 4 (very often), with a higher score implying more severe problematic Internet use. At-risk and problematic alcohol consumption were evaluated by the French Alcohol Use Disorders Identification Test (AUDIT; Gache et al., 2005; original English version: Allen, Litten, Fertig, \& Babor, 1997), consisting of 10 individual items measuring the severity of alcohol use. A higher score thus indicates more frequent/intense alcohol consumption.

\section{Statistical analyses}

All statistical analyses were performed with IBM SPSS Statistics 24 (IBM Corp, 2015). Subgroups of binge-watchers were determined as usually advised by means of data clustering executed via both hierarchical and non-hierarchical techniques (Hair, Black, Babin, \& Anderson, 2010). In the first step, a hierarchical analysis was conducted by applying Ward's clustering method based on squared Euclidean distances; then, cluster membership was identified in a second step with non-hierarchical K-means analysis. In accordance with the above theoretical rationale, the set of psychological variables of interest (i.e., TV series-watching motivations, impulsivity traits, and emotional reactivity) was used to form the clusters after prior $Z$-score transformation. In addition, upstream inspection of the correlations between each of these variables (the full correlational results are available from https://osf.io/x 849w/) did not note any significant multicollinearity issue $(r=.50$, constituting the uppermost correlation). Finally, the soundness of the resulting clusters 
Table 1. Questionnaire variables evaluated in the online survey

\begin{tabular}{|c|c|c|c|}
\hline Questionnaire & Scale & Scale description & $\begin{array}{l}\text { Reliability } \\
\text { coefficient }(\alpha)\end{array}$ \\
\hline Watching TV Series & Social & Interest in bonding with others by means of TV series & .69 \\
\hline \multirow[t]{3}{*}{ Motives Questionnaire } & $\begin{array}{l}\text { Emotional } \\
\text { enhancement }\end{array}$ & Desire to watch TV series to experience intense affective states & .64 \\
\hline & Enrichment & $\begin{array}{l}\text { Interest in developing one's intellectual experiences and } \\
\text { knowledge through TV series watching }\end{array}$ & .71 \\
\hline & Coping/escapism & $\begin{array}{l}\text { Desire to watch TV series to avoid thinking about real-life } \\
\text { problems or to cope with negative affect }\end{array}$ & .79 \\
\hline Binge-Watching & Engagement & Extent of involvement in TV series watching & .80 \\
\hline Engagement and & Positive emotions & Emotional benefits derived from TV series watching & .66 \\
\hline Symptoms & Desire/savoring & Amount of desire for and appreciation of TV series watching & .77 \\
\hline \multirow[t]{4}{*}{ Questionnaire } & Pleasure preservation & $\begin{array}{l}\text { Use of strategies aimed at maintaining or enhancing TV series } \\
\text { watching pleasure }\end{array}$ & .63 \\
\hline & Binge-watching & Extent of binge-watching & .79 \\
\hline & Loss of control & Problematic involvement in binge-watching & .82 \\
\hline & Dependency & Difficulty to abstain from TV series watching & .78 \\
\hline s-UPPS-P Impulsive & Negative urgency & Proneness to act rashly in intense negative emotional contexts & .84 \\
\hline \multirow[t]{4}{*}{ Behavior Scale } & Positive urgency & Proneness to act rashly in intense positive emotional contexts & .74 \\
\hline & Lack of premeditation & Difficulty to take into account the consequences of an action & .82 \\
\hline & Lack of perseverance & Difficulty to remain focused on difficult or boring tasks & .88 \\
\hline & Sensation seeking & $\begin{array}{l}\text { Openness to new experiences and preferences for risky } \\
\text { activities }\end{array}$ & .82 \\
\hline Emotion Reactivity Scale & Emotional reactivity & $\begin{array}{l}\text { Extent to which individuals experience emotions in response } \\
\text { to a wide array of stimuli, strongly or intensely, and for a } \\
\text { prolonged period of time before returning to baseline level of } \\
\text { arousal }\end{array}$ & .93 \\
\hline Positive Affect and & Negative affect & Proneness to experience negative affect states & .83 \\
\hline $\begin{array}{l}\text { Negative Affect } \\
\text { Schedule }\end{array}$ & Positive affect & Proneness to experience positive affect states & .74 \\
\hline $\begin{array}{l}\text { Compulsive Internet Use } \\
\text { Scale }\end{array}$ & $\begin{array}{l}\text { Problematic Internet } \\
\text { use }\end{array}$ & $\begin{array}{l}\text { Problematic involvement regarding Internet use (e.g., loss of } \\
\text { control, attentional focus, and interpersonal conflicts) }\end{array}$ & .91 \\
\hline $\begin{array}{l}\text { Alcohol Use Disorders } \\
\text { Identification Test }\end{array}$ & $\begin{array}{l}\text { Alcohol-related } \\
\text { problems }\end{array}$ & Hazardous and problematic alcohol use & .85 \\
\hline
\end{tabular}

Note. Internal reliability coefficients $(\alpha)$ obtained in the current sample.

was investigated through mutual comparisons of external correlates including (a) sociodemographics (age, gender, educational level, and marital status); (b) viewing patterns (frequency of viewing, average time spent viewing, usual number of episodes watched during one session, and typical number of shows followed simultaneously), self-perceived consumption (dependency, problematic extent, and willingness to modify the behavior), and preferences (most often watched genres) related to TV series; (c) reported involvement in binge-watching and problematic binge-watching (BWESQ); (d) affect (PANAS); (e) problematic Internet use (CIUS); and (f) alcohol-related problems (AUDIT). To do so, analyses of variance (ANOVAs) were undertaken, and Bonferroni-corrected post-hoc $t$-tests were computed.

\section{Ethics}

This study obtained clearance from the Psychological Sciences Research Institute Ethics Committee of the Université catholique de Louvain (Belgium). The aims of the study were specified to the participants who systematically gave their consent prior to anonymously taking part in the assessment. No incentives were provided to participants.
Part of the data collected in the online survey has already been published in a previous study testing the psychometric properties of the WTSMQ and the BWESQ scales described above (Flayelle, Canale, et al., 2019). Still, the findings presented here constitute original results as they are based on additional material that was not part of the aforementioned publication, which involved a distinct research objective.

\section{RESULTS}

The data clustering results derived from the agglomeration schedule, dendrogram, and scree plot (Yim \& Ramdeen, 2015) suggested an optimal four-factor solution at both statistical and theoretical levels. Additional analyses revealed that a three-factor solution would mask insightful findings by merging clusters 2 and 4, whereas a five-factor solution includes two very similar clusters. The psychological profiles of the four clusters identified are displayed in Figure 1. The subsequent ANOVAs emphasized that cluster membership has a significant effect on all psychological factors considered (i.e., TV series-watching motivations, 


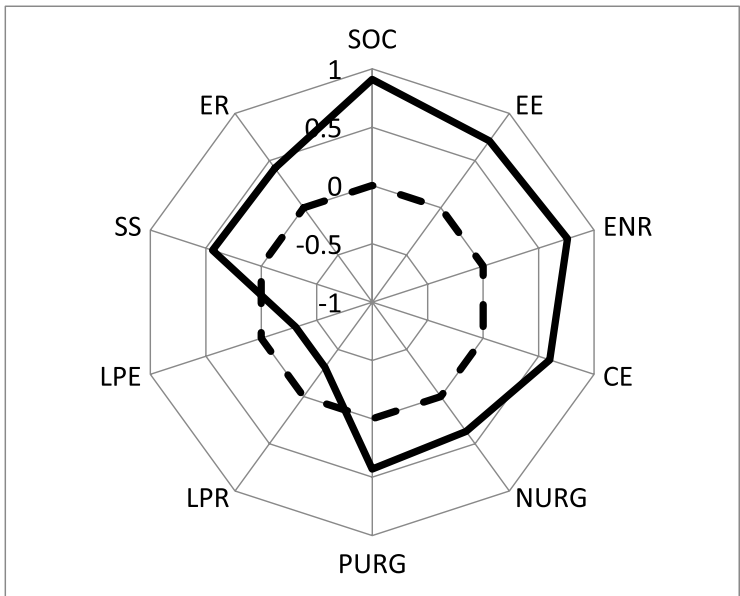

Cluster 1: Avid binge-watchers

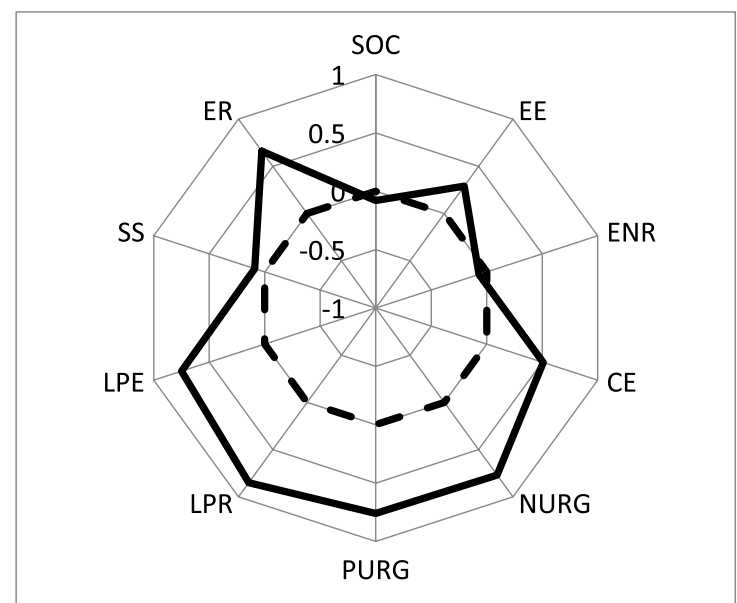

Cluster 3: Unregulated binge-watchers

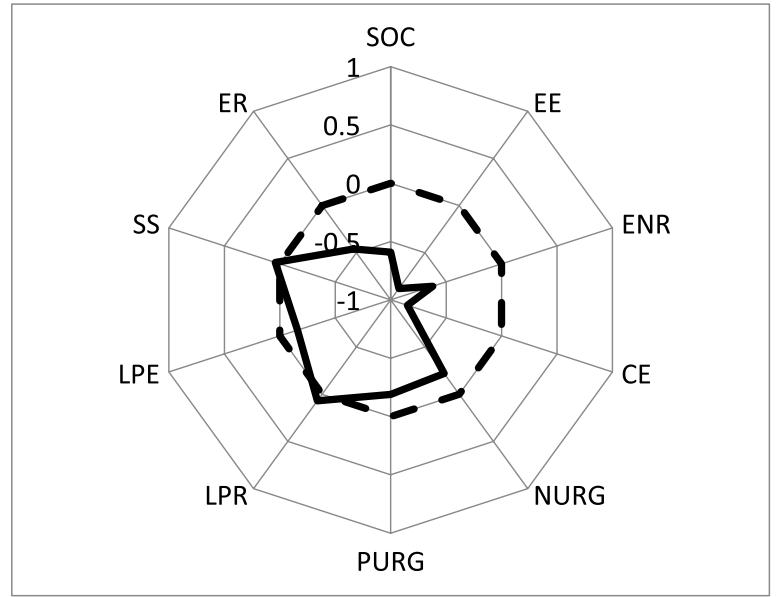

Cluster 2: Recreational TV series viewers

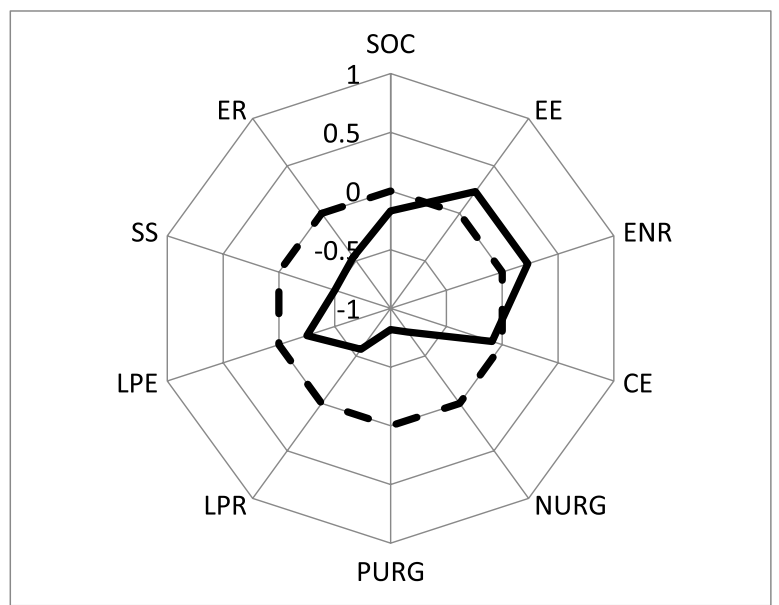

Cluster 4: Regulated binge-watchers

Figure 1. Psychological profiles of the subgroups of TV series viewers. Note. SOC: social (WTSMQ); EE: emotional enhancement (WTSMQ); ENR: enrichment (WTSMQ); CE: coping/escapism (WTSMQ); NURG: negative urgency (s-UPPS-P); PURG: positive urgency (s-UPPS-P); LPR: lack of premeditation (s-UPPS-P); LPE: lack of perseverance (s-UPPS-P); SS: sensation seeking (s-UPPS-P); ER: emotional reactivity (ERS). Dashed lines refer to mean $Z$-scores of the entire sample. Bold lines refer to mean $Z$-scores for each specific cluster

impulsivity dimensions, and emotional reactivity), and on all the external correlates (i.e., sociodemographics, viewing patterns, self-perceived consumption and preferences related to TV series, reported involvement in binge-watching and problematic binge-watching, affect, problematic Internet use, and alcohol-related problems). Descriptive statistics for each of these clusters and differences between them with regard to psychological characteristics and external correlates are shown in Table 2. The various genres of TV series mostly watched among the four clusters are displayed in Figure 2. These results are first presented in their raw form here before being interpreted and discussed in the following section.

On the whole, cluster 1 members were characterized by the highest levels of motivations for TV series watching, high urgency (both negative and positive) and the highest degree of sensation seeking, as well as high emotional reactivity. In contrast, members of cluster 2 reported the lowest motivations for TV series watching, low to moderate impulsivity traits, and low emotional reactivity. Affect-based motivations (i.e., emotional enhancement and coping/escapism) were the most pronounced among cluster 3 members, who also reported the highest scores on both impulsivity domains (with the exception of sensation seeking) and emotional reactivity. Members of cluster 4 were primarily motivated by emotional enhancement and enrichment for TV series watching, and were distinguished by low impulsivity traits and low emotional reactivity.

The results on external correlates showed that members of both clusters 1 and 3 tended to be younger, with members of cluster 2 being significantly older. Female viewers were also significantly more represented in cluster 3 compared with all other clusters. Concerning TV series-watching patterns, members of cluster 2 reported significantly less viewing, whereas members of both clusters 1 and 3 globally watched TV series more often and longer. They also watched more episodes back-to-back during one session, whereas members of cluster 2 reported watching 
Flayelle et al.

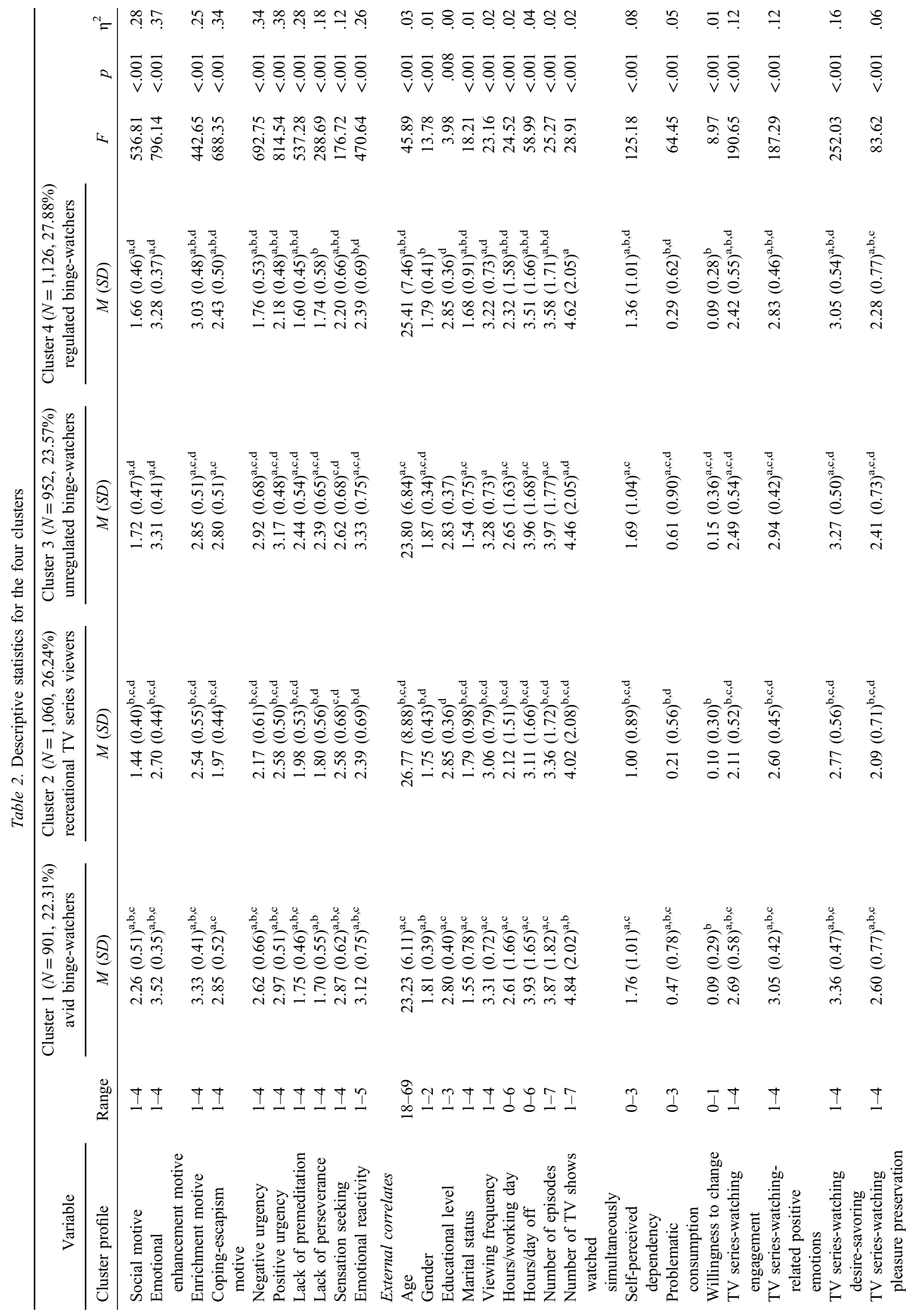


significantly fewer episodes consecutively. Members of cluster 3 considered their consumption of TV series as more problematic in comparison with other clusters. Coherently, cluster 3 members also reported significantly more planning to modify their pace of consumption of TV series, whereas the three other clusters indicated less willingness to change their viewing behavior. Overall, members of cluster 1 reported significantly higher levels of engagement, positive emotional experience, desire, pleasure preservation, and dependency related to TV series watching, followed by members of cluster 3 , then clusters 4 and 2. Cluster 2 members scored significantly lower on binge-watching, whereas members of both clusters 1 and 3 reported more binge-watching. Yet, cluster 3 members differed from cluster 1 as they scored significantly higher on loss of control than viewers belonging to the three other clusters, with, once again, members of cluster 2 being lowest. Cluster 3 members acknowledged significantly more negative affect over the past few months and also reported significantly more problematic Internet use and alcohol-related problems, as evidenced by the cluster comparisons. Finally, as to the genres of TV series they reported watching more, members of clusters 1 and 3 mentioned globally more drama and horror shows, and members of both clusters 1 and 4 mostly watched science fiction and fantasy genres. Detective series and historical shows were more popular among members of both clusters 2 and 4 , and finally cluster 1 members enjoyed more action/adventure shows, whereas cluster 3 members watched significantly more romance-oriented TV series.

\section{DISCUSSION AND CONCLUSIONS}

The aim of this study was to go beyond the unitary approach of binge-watching by identifying potential subgroups of binge-watchers through TV series-watching motivations, impulsivity traits, and emotional reactivity. Binge-watching has previously often been conceptualized a priori as an addictive disorder, thus engendering potential disease mongering while limiting the scope of its understanding. Therefore, this study aimed at subtyping binge-watching based on first-order psychological factors in a large sample of TV series viewers using a clusteranalytical approach. The results suggest a four-cluster solution with distinct viewers' profiles that exhibit unique psychological characteristics and specific patterns of external correlates.

The first cluster was composed of viewers characterized by the highest levels of motivations for TV series watching, elevated urgency traits (both positive and negative) and sensation seeking, as well as high emotional reactivity. As a subgroup of viewers who seem to make the most of binge-watching in a keen and trouble-free relationship with TV series, members of this cluster were named avid bingewatchers. Indeed, each TV series-watching motive was considered as essential by these viewers, which reflects how fundamental this leisure activity is for them in terms of needs fulfillment. Whether for the purpose of bonding with others outside viewing sessions (Flayelle et al., 2017; Panda \& Pandey, 2017; Tóth-Király et al., 2017), affect regulation via enjoyment or distraction (Pittman \& Sheehan, 2015; 

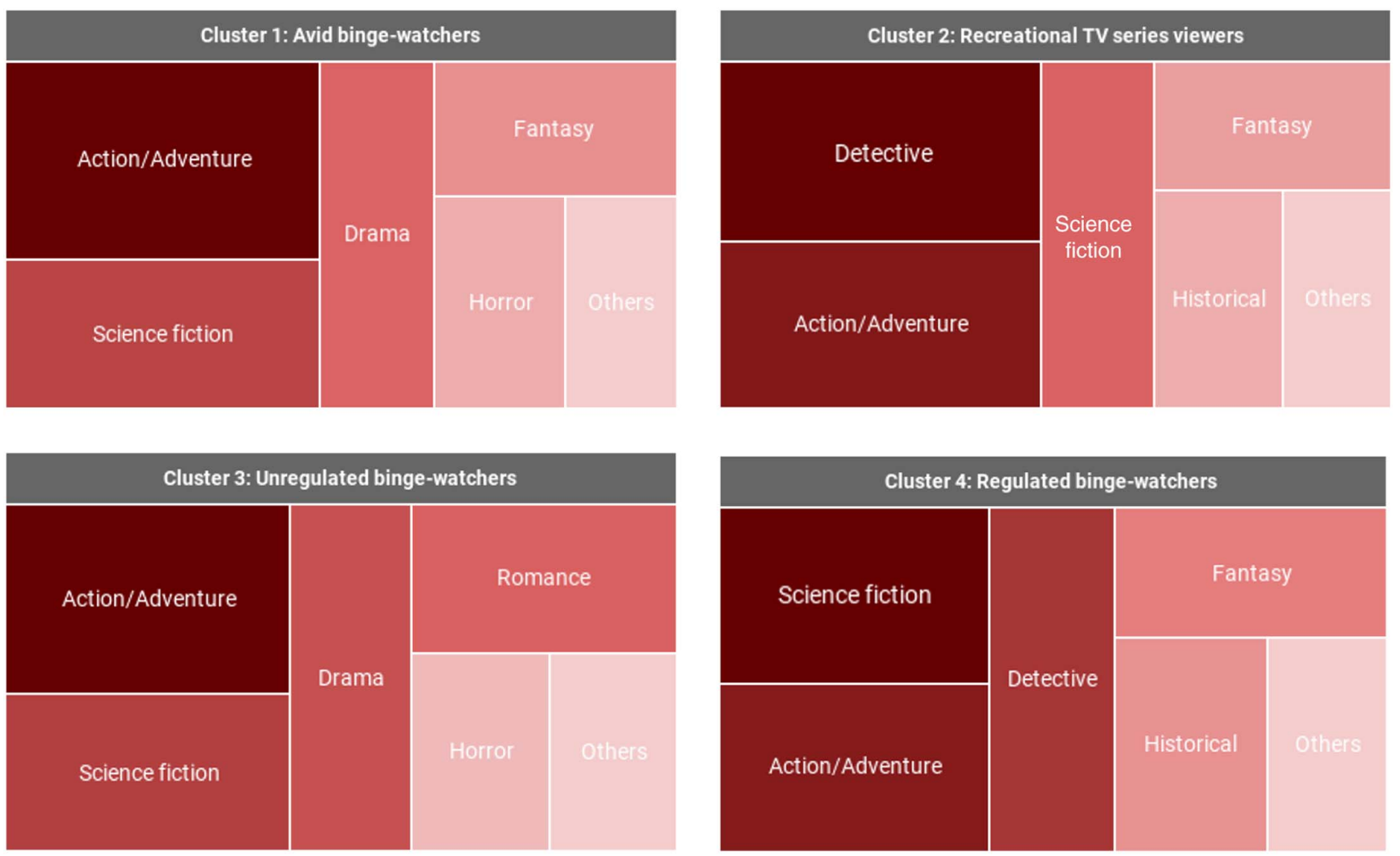

Figure 2. Genres of TV series most frequently watched among the four clusters. Note. The square sizes and color gradation refer to the strength of preference. The ANOVAs conducted emphasized a significant effect of cluster membership on each of the genres presented

Shao \& Beneza, 2018; Shim \& Kim, 2018), or personal enrichment (Adachi, Ryan, Frye, McClurg, \& Rigby, 2017; Mikos, 2016; Perks, 2015), TV series watching may be an essential part of viewers' everyday life, TV shows being perceived as veritable "companions" (Flayelle et al., 2017). Obviously, the cluster comparison at hand suggests that members of this subgroup fall within this category of viewers: they reported an extensive consumption with more frequency of viewing and more distinct TV series followed simultaneously, while feeling at the same time more dependent on them. They also displayed the highest scores in measures of the extent of interest in or wish for bingewatching (i.e., engagement, positive emotional experience, desire/savoring, and pleasure preservation) and of dependency on TV series. These genuine TV series' enthusiasts were also characterized by a remarkable impulsivity profile. On the one hand, they displayed high levels of both types of urgency. On the other hand, they also manifested high levels of premeditation and perseverance. This association is particularly insightful in the context of binge-watching given the proposal that an elevated urgency may arise from inhibitory difficulties that are induced or potentiated by an emotional context, or could result from such a high emotional reactivity that inhibitory capacities (preserved in non-emotional contexts) end up being reduced (Billieux et al., 2010; Johnson, Tharp, Peckham, Sanchez, \& Carver, 2016; Wilbertz et al., 2014). In this respect, it is noteworthy that avid binge-watchers were also distinguished by a heightened level of emotional reactivity. In addition, it has been suggested that urgency-related behaviors could be associated with difficulties to take into account the consequences of one's actions in emotional contexts (Billieux et al., 2010; Cyders \& Smith, 2008). Taken together, this suggests that, rather than depending on basal (presumably reduced or impaired) self-control capacities, these viewers' ability to decide whether or not they should keep watching "just one more" episode must be especially sensitive to the effects of the TV series at the very moment of watching (i.e., through the emotional impact generated by the storyline, notably with the concluding events of an episode). The higher rates of binge-watching they acknowledge (i.e., more hours spent viewing per session, more episodes seen back to back, higher scores on the bingewatching measure) support this interpretation. As to their impulsivity profile, it is also of interest that avid bingewatchers were characterized by the highest level of sensation seeking. Sensation seeking, which has been recently reported as a predictor of binge-watching (Shim \& Kim, 2018), relates more to motivational processes according to the multidimensional conceptualization of impulsivity (Rochat et al., 2018) and should reflect a global predominance of approach behaviors (rather than avoidance behaviors) as well as a marked sensitivity to rewards or to positive reinforcements (see, e.g., Joseph, Lin, Jiang, Lynam, \& Kelly, 2009; Torrubia, Avila, Molto, \& Caseras, 2001). This last consideration casts additional light on the reasons why these viewers would be more susceptible to binge-watching behavior given their foreseeable higher responsiveness to the immediate gratification provided by watching a subsequent episode. Furthermore, sensation seeking has been suggested as a driving factor to indulge in recreational activities (e.g., alcohol consumption and 
gambling) without necessarily contributing to the development of problematic behaviors (Smith et al., 2007). This is in line with the current result that avid binge-watchers reported lower scores on the loss of control measure and generally lower levels of agreement that their consumption of TV series was problematic.

In contrast, individuals in the second cluster were characterized by the lowest motivations for TV series watching, moderate impulsivity traits, and low emotional reactivity. Forming a subgroup of viewers apparently less involved with TV series, members of this cluster were named recreational TV series viewers. Indeed, the various TV serieswatching motivations took a subordinate place for this subgroup of viewers who were on average older and more established (i.e., more marital relationships, higher educational levels) than those in the other clusters. For individuals in this cluster, TV series watching presumably does not fulfill the primary function of needs satisfaction, and takes a more modest place in their everyday life, as suggested by their low scores on viewing extent and binge-watchingrelated measures. These more casual TV series viewers presented average levels of impulsivity in all its subcomponents as well as low emotional reactivity, which contributes to their low risk to engage in binge-watching behavior.

The third cluster is composed of viewers who reported more affect-based motivations for TV series watching, higher impulsive traits (but a moderate level of sensation seeking), and the highest level of emotional reactivity. As a subgroup of individuals whom both dispositional traits and drivers place them at risk for more compulsive and, potentially, problematic binge-watching, members of this cluster were named unregulated binge-watchers. With rates of motivations close to the average, these viewers greatly enjoy TV series for entertainment purposes. Nevertheless, their drive for TV series watching appears to be even more determined by the will to reduce negative emotions or to escape unpleasant affective states. Interestingly, like avid binge-watchers, this subgroup is composed of younger viewers who reported elevated viewing patterns, which is consistent with both the fact that escapism from reality has recently been acknowledged as a key motivation to spend more time with binge-watching (Panda \& Pandey, 2017; Rubenking et al., 2018; Starosta et al., 2019), and that young adults are often considered to be the most avid bingeviewers (Exelmans \& Van den Bulck, 2017; Spangler, 2016). However, setting aside the significance threshold, mean score differences between avid binge-watchers and unregulated binge-watchers are worth considering: while avid binge-watchers displayed a consumption of TV series much wider in scope with higher frequency and more TV series followed simultaneously, unregulated binge-watchers manifested a more constricted and intense consumption with more hours spent viewing and more episodes watched back-to-back during a single session. The simple observation of values similarly informs that unregulated bingewatchers self-reported slightly more binge-watching in comparison with avid binge-watchers. In view of previous findings from a large pool of TV series viewers showing that women are more likely than men to watch more episodes at a time (see Sigman, 2016), it may be also worth noting that this cluster had the highest proportion of female viewers. This needs to be seen in light of their particular impulsivity profile, given that diminished self-control capacities were fully reflected in this subgroup by the highest scores recorded on the impulsivity dimensions (i.e., positive and negative urgency, lack of perseverance, and lack of premeditation) referring more directly to the efficiency of executive mechanisms (e.g., inhibitory control) and decision-making processes (Rochat et al., 2018). Accordingly, in combination with the highest levels of emotional reactivity, unregulated binge-watchers may be more at risk of developing excessive and problematic patterns of bingewatching, by having trouble both resisting the urge to watch a subsequent episode and considering the consequences of getting drawn into a TV series for a longer time than intended. This is supported by external correlates, which show that these viewers not only acknowledged more loss of control over their viewing, but also considered their consumption of TV series as more problematic and more likely to be in need to be amended. In addition, as if to stressing their at-risk profile, unregulated binge-watchers also reported more problematic behaviors (i.e., compulsive Internet use and alcohol-related problems). In light of these results, and further supported by the observation that these viewers were primarily motivated by coping/escapism for TV series watching while declaring simultaneously more negative and less positive affects, it is likely that, for them, excessive binge-watching constitutes an emotion regulation strategy to cope with negative affective states (Flayelle, Maurage, et al., 2019; Rubenking \& Bracken, 2018; Tukachinsky \& Eyal, 2018). In this context, it is worth recalling the high prevalence of female viewers within this subgroup, which may be related to the higher rates of depression in women (Albert, 2015; Cyranowski, Frank, Young, \& Shear, 2000; Nolen-Hoeksema, 1990). In addition, there is evidence for positive associations between depression and binge-watching (Ahmed, 2017; Tukachinsky \& Eyal, 2018), with the effect of depression being fully mediated by self-control deficiency (Tukachinsky \& Eyal, 2018).

Members of the fourth cluster were primarily motivated by emotional enhancement and enrichment through TV series watching, and were characterized by low scores on all impulsivity dimensions and low emotional reactivity. Constituting a subgroup of TV series viewers with a particular interest in binge-watching but for whom moderation is key, members of this cluster were named regulated bingewatchers. Mostly driven by the parallel pleasures of entertainment and personal enrichment, regulated bingewatchers form the category of more "purist" viewers who engage in binge-watching for the gratifications that media use typically has to offer. Indeed, it is well established that selective entertainment media exposure in everyday life is motivated by both mood optimization (i.e., mood management theory; Zillmann, 1988, 2000) and the search for eudaimonic enjoyment whereby one is gaining greater insight and meaningfulness while being moved by the media content (Oliver \& Bartsch, 2010; Oliver \& Raney, 2011; Wirth, Hofer, \& Schramm, 2012). Nevertheless, neither too much nor too little in comparison with other clusters' members, these viewers' extent of TV series consumption always falls within the average range of rates, just as their 
scores on self-reported binge-watching measures. This seeming temperance in binge-watching behavior was well reflected in their lower scores on all impulsivity dimensions and emotional reactivity. As genuine regulation-oriented individuals, it is worth noting that they also manifested the highest level of premeditation and lowest degree of alcoholrelated problems.

Accounting for the various genres of TV series differentially favored by members of the four clusters gives further substance to the foregoing considerations. Although genres of TV series are mostly hybrids (i.e., mixing elements of several genres at once), such literary subdivision still seems appropriate in light of the current clusters. As for avid bingewatchers, it is noteworthy that their favored categories (i.e., action/adventure, science fiction, drama, fantasy, and horror) were predominantly of story-driven nature, proposing long-term narratives that stretch overarching storylines across multiple episodes, a whole season or even the entire TV series. Meant as a set that always remains to be complemented, every single episode in this kind of storytelling leaves unresolved questions (by means of striking cliffhangers) that will be answered later, thus giving rise to suspense and leading to strong expectations about the outcome. The tendency to get absorbed into suspenseful stories and to keep watching to see how the storyline unfolds (Knobloch-Westerwick \& Keplinger, 2007) might explain the higher rates of binge-watching reported by this cluster. More recently, binge-watching (regardless of content) has also been found to be preferred when individual episodes are perceived to be interconnected as opposed to when events are independent with points of closure $(\mathrm{Lu}$, Karmarkar, \& Venkatraman, 2017). Not only insightful with respect to viewing patterns, avid binge-watchers' preferences are also quite illustrative of the psychological features that characterize this subgroup of viewers. Their preference for high-energy narratives with acute stakes (i.e., action/ adventure) and series with twisty plots and tense atmosphere (i.e., horror) somehow bears witness to their higher level of sensation seeking. Preceding research has, for example, shown that sensation seeking predicts horror's appeal (Aluja-Fabregat, 2000; Tamborini \& Stiff, 1987; Zuckerman, 1996), and that arousal in high sensation seekers increases significantly during exposure to horror (Tamborini, Miller, Stiff, \& Heidel, 1988). Beyond sensation seeking, their reported appetite for science fiction and fantasy genres may also reflect their greater use of TV series watching for personal enrichment as, while being transported to parallel worlds (e.g., possible futures and supernatural universe), viewers follow the course of varied events often organized and focused around resonant, eudaimonic themes, that convey meaningful and intellectually stimulating messages (Russin \& Missouri, 2012). This latter connection is best exemplified by the viewing preferences of regulated binge-watchers (here known to primarily seek eudaimonic enjoyment through TV series watching) that also lie on the side of thought-provoking and horizonwidening types of shows (i.e., science fiction, detective, fantasy, and historical). For their part, unregulated binge-watchers had in common with avid binge-watchers to watch more programs (i.e., drama and horror) that deliver linearly progressing storylines, where prolonged cliffhangers maintain long-term suspense, but especially where emotional impact reaches its peak. Indeed, previous studies indicated that viewers exposed to horror undergo an exhilarating emotional experience (Tamborini, 2003; Tamborini et al., 1988) and that, relative to other genres, drama tends to be associated with greater emotional arousal (Oliver \& Bartsch, 2010; Till, Niederkrotenthaler, Herberth, Vitouch, \& Sonneck, 2010). Specific for individuals in this subgroup of TV series viewers, however, is their significantly more pronounced proneness to immerse themselves in romance-oriented TV shows, where the interconnectedness of episodes most often addresses the protagonists' love affairs. This is a special feature that is arguably deducible from the fact that this subgroup had the highest proportion of female viewers, given the existence of reliable gender differences identified by research with respect to romantic media preferences (Greenwood, 2010; Oliver, Sargent, \& Weaver, 1998; Wühr, Lange, \& Schwarz, 2017). Finally, of particular interest remains that detective shows constituted the only category of programs for which the viewers who were characterized either by a minor (i.e., recreational $T V$ series viewers) or moderate (i.e., regulated bingewatchers) proneness to engage in binge-watching reported more inclination. In fact, police-procedural TV series typically consist in stand-alone episodes where the plots follow the investigative procedure, thus delivering closed in themselves stories with a beginning and a resolution (i.e., solving the crime). More broadly characterized as pure intellectual animation lacking emotional appeal (due to its emphasis on reasoning and puzzle-solving; Knobloch, 2003; Smyer, 1999), the fact that this type of TV series only stands out on the side of the more moderate viewers comes as a further support to all the above reasoning.

Taken together, the current clustering results suggest that subtyping of binge-watchers according to TV serieswatching motivations, multidimensional impulsivity, and emotional reactivity may be a theoretically sound way of capturing the diversity among non-problematic and problematic binge-watchers, thereby stressing the heterogeneous and multidetermined nature of binge-watching (Flayelle et al., 2017). More importantly, these findings emphasize that, beyond similar elevated viewing patterns, avid bingewatching is utterly distinct from problematic binge-watching, which lends strong support to the view that conceptualizing high binge-watching as an addictive disorder from the outset is not just ill-suited but prejudicial as this amounts to pathologizing a popular leisure activity one may be just passionate about. Rather, from a psychological processesbased perspective (e.g., Kinderman, 2005), our results draw a clear distinction between high binge-watchers by setting apart the ones who, greatly receptive to what is happening during viewing (i.e., under the direct influence of TV series), are giving in to binge-watching for better, and the others whom poor self-control and emotional regulation difficulties make them more vulnerable to develop excessive or problematic patterns of binge-watching. In this context, the results of this study echo previous findings showing that media marathon viewing is not necessarily dysfunctional, but can also testify of a very reflective and meaningful experience (Tukachinsky \& Eyal, 2018), and that more generally high (but healthy) 
involvement has to be distinguished from problematic involvement, or addiction, with regard to recreational behaviors (e.g., problematic use of video games; Billieux, Flayelle, Rumpf, \& Stein, 2019; Charlton \& Danforth, 2007).

The present findings also have clinical implications by suggesting that interventions devoted to both the establishment of adaptive emotion regulation strategies and the improvement of self-control capacities would be prime candidates for the treatment of problematic binge-watching. Still, several limitations of this study need to be acknowledged. First, in view of its cross-sectional nature, further longitudinal research is required to support the soundness of the four clusters. Moreover, this study relied on self-reported data, which implies typical limitations such as social desirability or differing self-perception of binge-watching severity and consequences. Objective measures of the psychological characteristics considered (e.g., laboratory behavioral measures of impulsivity, physiological assessment of emotional reactivity) are therefore needed in future investigations. It is also worth noting that data clustering techniques do not allow for the examination of causal relationships between constructs. Finally, forthcoming studies should consider a more comprehensive assessment of psychological factors (e.g., other types of personality traits) to further explore binge-watchers' subprofiles.

Overall, this study identified distinct valid subgroups of binge-watchers on the basis of first-order psychological factors. Through a careful back and forth comparison of their psychological characteristics and correlates, an indepth examination of each profile allowed for a veritable disentangling of binge-watching behaviors as well as for improving the understanding of what motivates problem binge-watching. In doing so, we further approached the complexity of binge-watching, which can no longer be conceptualized as a unitary behavioral manifestation, and whose investigation must go beyond mere surface-based approaches.

Funding sources: The work of Pierre Maurage (Senior Research Associate) is funded by the Belgian Fund for Scientific Research (FRS-FNRS, Belgium).

Authors' contribution: MF, PM, and JB designed the study and interpreted the results. MF created and disseminated the online survey (with the help of LK) and ran the statistical analyses. She also wrote the initial draft of the article, under the supervision of PM and JB. JB, PM, LK, and CV reviewed the initial draft and participated in the writing of the final draft. All authors approved the final version of the manuscript.

Conflict of interest: The authors declare no conflict of interest.

\section{REFERENCES}

Adachi, P. J. C., Ryan, R. M., Frye, J., McClurg, D., \& Rigby, C. S. (2017). "I can't wait for the next episode!": Investigating the motivational pull of television dramas through the lens of SelfDetermination Theory. Motivation Science, 4(1), 78-94. doi:10.1037/mot0000063

Ahmed, A. (2017). New era of TV-watching behavior: Binge-watching and its psychological effects. Media Watch, 8, 192-207. doi:10.15655/mw/2017/v8i2/49006

Albert, P. R. (2015). Why is depression more prevalent in women? Journal of Psychiatry \& Neuroscience, 40(4), 219-221. doi:10.1503/jpn.150205

Allen, J. P., Litten, R. Z., Fertig, J. B., \& Babor, T. (1997). A review of research on the Alcohol Use Disorders Identification Test (AUDIT). Alcoholism, Clinical and Experimental Research, 21(4), 613-619. doi:10.1111/j.1530-0277.1997. tb03811.x

Alter, A. (2017). Irresistible: The rise of addictive technology and the business of keeping us hooked. New York, NY: Penguin Press.

Aluja-Fabregat, A. (2000). Personality and curiosity about TV and films violence in adolescents. Personality and Individual Differences, 29(2), 379-392. doi:10.1016/S0191-8869(99) 00200-7

Anestis, M. D., Selby, E. A., \& Joiner, T. E. (2007). The role of urgency in maladaptive behaviors. Behaviour Research and Therapy, 45(12), 3018-3029. doi:10.1016/j.brat.2007.08.012

Berg, J. M., Latzman, R. D., Bliwise, N. G., \& Lilienfeld, S. O. (2015). Parsing the heterogeneity of impulsivity: A meta-analytic review of the behavioral implications of the UPPS for psychopathology. Psychological Assessment, 27(4), 1129-1146. doi:10.1037/pas0000111

Billieux, J., Flayelle, M., Rumpf, H. J., \& Stein, D. (2019). High involvement versus pathological involvement in video games: A crucial distinction for ensuring the validity and utility of gaming disorder. Current Addiction Reports, 6(3), 323-330. doi:10.1007/s40429-019-00259-x

Billieux, J., Gay, P., Rochat, L., \& Van der Linden, M. (2010). The role of urgency and its underlying psychological mechanisms in problematic behaviours. Behaviour Research and Therapy, 48(11), 1085-1096. doi:10.1016/j.brat.2010.07.008

Billieux, J., Philippot, P., Schmid, C., Maurage, P., de Mol, J., \& Van der Linden, M. (2015). Is dysfunctional use of the mobile phone a behavioural addiction? Confronting symptom-based versus process-based approaches. Clinical Psychology and Psychotherapy, 22(5), 460-468. doi:10.1002/cpp.1910

Billieux, J., Rochat, L., Ceschi, G., Carré, A., Offerlin-Meyer, I., Defeldre, A.C., Khazaal, Y., Besche-Richard, C., \& Van der Linden, M. (2012). Validation of a short French version of the UPPS-P Impulsive Behavior Scale. Comprehensive Psychiatry, 53(5), 609-615. doi:10.1016/j.comppsych.2011.09.001

Billieux, J., Schimmenti, A., Khazaal, Y., Maurage, P., \& Heeren, A. (2015). Are we overpathologizing everyday life? A tenable blueprint for behavioral addiction research. Journal of Behavioral Addictions, 4(3), 119-123. doi:10.1556/2006.4.2015.009

Canale, N., Vieno, A., Griffiths, M. D., Rubaltelli, E., \& Santinello, M. (2015). How do impulsivity traits influence problem gambling through gambling motives? The role of perceived gambling risk/benefits. Psychology of Addictive Behaviors, 29(3), 813-823. doi:10.1037/adb0000060

Charlton, J. P., \& Danforth, I. D. W. (2007). Distinguishing addiction and high engagement in the context of online game playing. Computers in Human Behavior, 23(3), 1531-1548. doi:10.1016/j.chb.2005.07.002 
Cyders, M. A., \& Smith, G. T. (2008). Emotion-based dispositions to rash action: Positive and negative urgency. Psychological Bulletin, 134(6), 807-828. doi:10.1037/a0013341

Cyranowski, J. M., Frank, E., Young, E., \& Shear, M. K. (2000). Adolescent onset of the gender difference in lifetime rates of major depression: A theoretical model. Archives of General Psychiatry, 57(1), 21-27. doi:10.1001/archpsyc.57.1.21

Dawe, S., \& Loxton, N. J. (2004). The role of impulsivity in the development of substance use and eating disorders. Neuroscience and Biobehavioral Reviews, 28(3), 343-351. doi:10. 1016/j.neubiorev.2004.03.007

De Feijter, D., Khan, J. V., \& Van Gisbergen, M. S. (2016). Confessions of a 'guilty' couch potato: Understanding and using context to optimize binge-watching behavior. Paper presented at TVX ' 16 Proceedings of the ACM International Conference on Interactive Experiences for TV and Online Video, Chicago, IL.

Dill, K. (Ed.). (2013). The Oxford handbook of media psychology. New York, NY: Oxford University Press.

Enticott, P. G., \& Ogloff, J. R. P. (2006). Elucidation of impulsivity. Australian Psychologist, 41(1), 3-14. doi:10.1080/ 00050060500391894

Exelmans, L., \& Van den Bulck, J. (2017). Binge viewing, sleep, and the role of pre-sleep arousal. Journal of Clinical Sleep Medicine, 13, 1001-1008. doi:10.5664/jcsm.6704

Field, S. (2005). Screenplay: The foundations of screenwriting. Paris, France: Delta Editions.

Flayelle, M., Canale, N., Vögele, C., Karila, L., Maurage, P., \& Billieux, J. (2019). Assessing binge-watching behaviors: Development and validation of the "Watching TV Series Motives" and "Binge-Watching Engagement and Symptoms" Questionnaires. Computers in Human Behavior, 90, 26-36. doi:10.1016/j.chb.2018.08.022

Flayelle, M., Maurage, P., \& Billieux, J. (2017). Toward a qualitative understanding of binge-watching behaviors: A focus group approach. Journal of Behavioral Addictions, 6(4), 457-471. doi:10.1556/2006.6.2017.060

Flayelle, M., Maurage, P., Vögele, C., Karila, L., \& Billieux, J. (2019). Time for a plot twist: Beyond confirmatory approaches to binge-watching research. Psychology of Popular Media Culture, 8(3), 308-318. doi:10.1037/ppm0000187

Gache, P., Michaud, P., Landry, U., Accietto, C., Arfaoul, S., Wenger, O., \& Daeppen, J. B. (2005). The Alcohol Use Disorders Identification Test (AUDIT) as a screening tool for excessive drinking in primary care: Reliability and validity of a French version. Alcoholism: Clinical and Experimental Research, 29(11), 2001-2007. doi:10.1097/01.alc.0000187034. 58955.64

Gaudreau, P., Sanchez, X., \& Blondin, J.-P. (2006). Positive and negative affective states in a performance-related setting: Testing the factorial structure of the PANAS across two samples of French-Canadian participants. European Journal of Psychological Assessment, 22(4), 240-249. doi:10.1027/ 1015-5759.22.4.240

Granow, V., Reinecke, L., \& Ziegele, M. (2018). Binge-watching $\&$ psychological well-being: Media use between lack of control and perceived autonomy. Communication Research Reports, 35(5), 392-401. doi:10.1080/08824096.2018.1525347

Greenberg, B. S., Neuendorf, K., Rothfuss, N. B., \& Henderson, L. (1982). The soaps: What's on and who cares? Journal of Broadcasting \& Electronic Media, 26, 519-535. doi:10.1080/ 08838158209364022
Greenwood, D. (2010). Of sad men and dark comedies: Mood and gender effects on entertainment media preferences. Mass Communication \& Society, 13(3), 232-249. doi:10.1080/ 15205430903186526

Hair, J. F., Black, W. C., Babin, B. J., \& Anderson, R. E. (2010). Multivariate data analysis: A global perspective. London, UK: Pearson Education.

Hasan, R., Kumar Jha, A., \& Liu, Y. (2018). Excessive use of online video streaming services: Impact of recommender system use, psychological factors, and motives. Computers in Human Behavior, 80, 220-228. doi:10.1016/j.chb.2017.11.020

Hernández Pérez, J. F., \& Martínez Díaz, M. A. (2016). Nuevos modelos de consumo audiovisual: los efectos del bingewatching sobre los jóvenes universitarios [New forms of audiovisual consumption: Binge watching effects on university students]. Revista Cientíca de Estrategias, Tendencias e Innovación en Comunicación, 13, 201-221. doi:10.6035/ 21740992.2017.13.11

Hofmann, W., Reinecke, L., \& Meier, A. (2017). Of sweet temptations and bitter aftertaste: Self-control as a moderator of the effects of media use on well-being. In L. Reinecke \& M. B. Oliver (Eds.), The Routledge handbook of media use and well-being: International perspectives on theory and research on positive media effects (pp. 211-222). New York, NY: Routledge.

Hofmann, W., Vohs, K. D., \& Baumeister, R. F. (2012). What people desire, feel conflicted about, and try to resist in everyday life. Psychological Science, 23(6), 582-588. doi:10.1177/ 0956797612437426

IBM Corp. (2015). IBM SPSS Statistics for Windows (version 24.0). Armonk, NY: IBM Corp.

Iglesias, K. (2005). Writing for emotional impact: Advanced dramatic techniques to attract, engage, and fascinate the reader from beginning to end. Livermore, CA: WingSpan Press.

Johnson, S. L., Tharp, J. A., Peckham, A. D., Sanchez, A. H., \& Carver, C. S. (2016). Positive urgency is related to difficulty inhibiting prepotent responses. Emotion, 16(5), 750-759. doi:10.1037/emo0000182

Joseph, J. E., Lin, X., Jiang, Y., Lynam, D. R., \& Kelly, T. H. (2009). Neural correlates of emotional reactivity in sensation seeking. Psychological Science, 20(2), 215-223. doi:10.1111/ j.1467-9280.2009.02283.x

Kardefelt-Winther, D. (2014). A conceptual and methodological critique of Internet addiction research: Towards a model of compensatory internet use. Computers in Human Behaviors, 31, 351-354. doi:10.1016/j.chb.2013.10.059

Kardefelt-Winther, D., Heeren, A., Schimmenti, A., van Rooij, A., Maurage, P., Carras, M., Edman, J., Blaszczynski, A., Khazaal, Y., \& Billieux, J. (2017). How can we conceptualize behavioural addiction without pathologizing common behaviours? Addiction, 112(10), 1709-1715. doi:10.1111/add.13763

Katz, E., Blumler, J. G., \& Gurevitch, M. (1973). Uses and gratifications research. Public Opinion Quarterly, 37(4), 509-523. doi:10.1086/268109

Khazaal, Y., Chatton, A., Horn, A., Achab, S., Thorens, G., Zullino, D., \& Billieux, J. (2012). French validation of the Compulsive Internet Use Scale (CIUS). Psychiatric Quarterly, 83(4), 397-405. doi:10.1007/s11126-012-9210-x

Kinderman, P. (2005). A psychological model of mental disorder. Harvard Review of Psychiatry, 13(4), 206-217. doi:10.1080/ 10673220500243349 
Knobloch, S. (2003). Suspense and mystery. In J. Bryant, D. R. Roskos-Ewoldsen, \& J. Cantor (Eds.), LEA's communication series. Communication and emotion: Essays in honor of Dolf Zillmann (pp. 379-395). Mahwah, NJ: Lawrence Erlbaum Associates.

Knobloch-Westerwick, S. (2015). Choice and preference in media use. New York, NY: Routledge.

Knobloch-Westerwick, S., \& Keplinger, C. (2007). Thrilling news: Factors generating suspense during news exposure. Media Psychology, 9(1), 193-210. doi:10.1080/15213260 709336809

Konijn, E. A. (2012). The role of emotions in media use and effects. In K. Dill (Ed.), The Oxford handbook of media psychology (pp. 186-211). New York, NY: Oxford University Press.

Lannoy, S., Heeren, A., Rochat, L., Rossignol, M., Van der Linden, M., \& Billieux, J. (2014). Is there an all-embracing construct of emotion reactivity? Adaptation and validation of the Emotion Reactivity Scale among a French-speaking community sample. Comprehensive Psychiatry, 55(8), 1960-1967. doi:10.1016/j.comppsych.2014.07.023

Lu, J., Karmarkar, U., \& Venkatraman, V. (2017). Planning to binge: How consumers choose to allocate time to view sequential versus independent media content. In A. Gneezy, V. Griskevicius, \& P. Williams (Eds.), Advances in consumer research (pp. 96-100). Duluth, MN: Association for Consumer Research.

McKee, R. (2010). Story: Substance, structure, style and the principles of screenwriting. Paris, France: Dixit Editions.

Meerkerk, G. J., Van Den Eijnden, R. J., Vermulst, A. A., \& Garretsen, H. F. (2009). The Compulsive Internet Use Scale (CIUS): Some psychometric properties. CyberPsychology \& Behavior, 12(1), 1-6. doi:10.1089/cpb.2008.0181

Mikos, L. (2016). Digital media platforms and the use of TV content: Binge watching and video-on-demand in Germany. Media and Communication, 4(3), 154-161. doi:10.17645/ mac.v4i3.542

Minear, M., Brasher, F., McCurdy, M., Lewis, J., \& Younggren, A. (2013). Working memory, fluid intelligence, and impulsiveness in heavy media multitaskers. Psychonomic Bulletin \& Review, 20(6), 1274-1281. doi:10.3758/s13423-013-0456-6

Nabi, R. I. (2009). Emotion and media effects. In R. I. Nabi \& M. B. Oliver (Eds.), The SAGE handbook of media processes and effects (pp. 205-221). Newbury Park, CA: Sage.

Netflix Media Center. (2019). About Netflix. Retrieved from https:// media.netflix.com/en/about-netflix

Nock, M. K., Wedig, M. M., Holmberg, E. B., \& Hooley, J. M. (2008). The Emotion Reactivity Scale: Development, evaluation, and relation to self-injurious thoughts and behaviors. Behavior Therapy, 39(2), 107-116. doi:10.1016/j.beth. 2007.05.005

Nolen-Hoeksema, S. (1990). Sex differences in depression. Stanford, CA: Stanford University Press.

Oliver, M. B., \& Bartsch, A. (2010). Appreciation as audience response: Exploring entertainment gratifications beyond hedonism. Human Communication Research, 36(1), 53-81. doi:10.1111/j.1468-2958.2009.01368.x

Oliver, M. B., \& Raney, A. A. (2011). Entertainment as pleasurable and meaningful: Identifying hedonic and eudaimonic motivations for entertainment consumption. Journal of Communication, 61(5), 984-1004. doi:10.1111/j.1460-2466.2011.01585.x
Oliver, M. B., Sargent, S., \& Weaver, J. B. (1998). The impact of sex and gender role self-perception on affective reactions to different types of film. Sex Roles, 38(1/2), 45-62. doi:10.1023/ A:1018760427785

Orosz, G., Bőthe, B., \& Tóth-Király, I. (2016). The development of the Problematic Series Watching Scale (PSWS). Journal of Behavioral Addictions, 5(1), 144-150. doi:10.1556/2006. 5.2016 .011

Panda, S., \& Pandey, S. C. (2017). Binge-watching and college students: Motivations and outcomes. Young Consumers, 18(4), 425-438. doi:10.1108/YC-07-2017-00707

Panek, E. (2014). Left to their own devices: College students' "guilty pleasure" media use and time management. Communication Research, 41(4), 561-577. doi:10.1177/00936502 13499657

Perks, L. G. (2015). Media marathoning: Immersions in morality. Lanham, MD: Lexington Books.

Pessoa, L. (2009). How do emotion and motivation direct executive control? Trends in Cognitive Sciences, 13(4), 160-166. doi:10.1016/j.tics.2009.01.006

Pittman, M., \& Sheehan, K. (2015). Sprinting a media marathon: Uses and gratifications of binge-watching television through Netflix. First Monday, 20. doi:10.5210/fm.v20i10.6138

Reinecke, L., \& Hofmann, W. (2016). Slacking off or winding down? An experience sampling study on the drivers and consequences of media use for recovery versus procrastination. Human Communication Research, 42(3), 441-461. doi:10. 1111/hcre. 12082

Riddle, K., Peebles, A., Davis, C., Xu, F., \& Schroeder, E. (2017). The addictive potential of television binge-watching: Comparing intentional and unintentional binges. Psychology of Popular Media Culture, 7(4), 589-604. doi:10.1037/ppm0000167

Rochat, L., Billieux, J., Gagnon, J., \& Van der Linden, M. (2018). A multifactorial and integrative approach to impulsivity in neuropsychology: Insights from the UPPS model of impulsivity. Journal of Clinical and Experimental Neuropsychology, 40(1), 45-61. doi:10.1080/13803395.2017.1313393

Rubenking, B., \& Bracken, C. C. (2018). Binge-watching: A suspenseful, emotional, habit. Communication Research Reports, 35(5), 381-391. doi:10.1080/08824096.2018.1525346

Rubenking, B., Bracken, C. C., Sandoval, J., \& Rister, A. (2018). Defining new viewing behaviours: What makes and motivates TV binge-watching? International Journal of Digital Television, 9(1), 69-85. doi:10.1386/jdtv.9.1.69_1

Rubin, A. M. (2009). Uses-and-gratifications perspective on media effects. In J. Bryant \& M. B. Oliver (Eds.), Media effects: Advances in theory and research (pp. 165-184). New York, NY: Routledge.

Russin, R. U., \& Missouri, W. (2012). Screenplay: Writing the picture. Los Angeles, CA: Silman-James Press.

Schnauber-Stockmann, A., Meier, A., \& Reinecke, L. (2018). Procrastination out of habit? The role of impulsive versus reflective media selection in procrastinatory media use. Media Psychology, 21(4), 640-668. doi:10.1080/15213269.2018. 1476156

Selby, E. A., Anestis, M. D., \& Joiner, T. E. (2008). Understanding the relationship between emotional and behavioral dysregulation: Emotional cascades. Behaviour Research and Therapy, 46(5), 593-611. doi:10.1016/j.brat.2008.02.002

Shao, C., \& Beneza, P. M. (2018, August). Binge-watching: Social and psychological factors behind audience's binging 
behaviour. Paper presented at the AEJMC Annual Conference, Washington, DC.

Shim, H., \& Kim, K. J. (2018). An exploration of the motivations for binge-watching and the role of individual differences. Computers in Human Behaviors, 82, 94-100. doi:10.1016/j.chb.2017.12.032

Shim, H., Lim, S., Jung, E. E., \& Shin, E. (2018). I hate bingewatching but I can't help doing it: The moderating effect of immediate gratification and need for cognition on bingewatching attitude-behavior relation. Telematics and Informatics, 35(7), 1971-1979. doi:10.1016/j.tele.2018.07.001

Sigman, L. (2016). Women are bigger binge-watchers. Retrieved from https://us.kantar.com/tech/tv/2016/tv-consumer-bingewatching-habits/

Silk, J. S., Steinberg, L., \& Morris, A. S. (2003). Adolescents' emotion regulation in daily life: Links to depressive symptoms and problem behavior. Child Development, 74(6), 1869-1880. doi:10.1046/j.1467-8624.2003.00643.x

Smith, G. T., Fischer, S., Cyders, M. A., Annus, A. M., Spillane, N. S., \& McCarthy, D. M. (2007). On the validity and utility of discriminating among impulsivity-like traits. Assessment, 14(2), 155-170. doi:10.1177/1073191106295527

Smyer, R. (1999). Escapism. In R. Herbert, C. Aird, J. M. Reilly, \& S. Oleksiw (Eds.), The Oxford companion to crime and mystery writing (pp. 303-304). New York, NY: Oxford University Press.

Spangler, T. (2016). Binge nation: 70\% of Americans engage in marathon TV viewing. Retrieved from https://variety.com/2016/ digital/news/binge-watching-us-study-deloitte-1201737245/

Starcevic, V., Billieux, J., \& Schimmenti, A. (2018). Selfitis, selfie addiction, Twitteritis: Irresistible appeal of medical terminology for problematic behaviours in the digital age. Australian and New Zealand Journal of Psychiatry, 52(5), 408-409. doi:10.1177/0004867418763532

Starosta, J., Izydorczyk, B., \& Lizińczyk, S. (2019). Characteristics of people's binge-watching behavior in the "entering into early adulthood" period of life. Health Psychology Report, 7(2), 149-164. doi:10.5114/hpr.2019.83025

Sung, Y. H., Kang, E. Y., \& Wee, L. (2018). Why do we indulge? Exploring motivations for binge watching. Journal of Broadcasting \& Electronic Media, 62(3), 408-426. doi:10.1080/ 08838151.2018.1451851

Tamborini, R. (2003). Enjoyment and social functions of horror. In J. Bryant, D. R. Roskos-Ewoldsen, \& J. Cantor (Eds.), Communication and emotion: Essays in honor of Dolf Zillmann (pp. 417-443). New York, NY: Routledge Taylor \& Francis Group.

Tamborini, R., Miller, K., Stiff, J., \& Heidel, C. (1988, May). Predictors of emotional reactions to audio and visual elements in graphic horror: A time series analysis. Paper presented at the annual conference of the Speech Communication Association, New Orleans, LA.

Tamborini, R., \& Stiff, J. (1987). Predictors of horror film attendance and appeal: An analysis of the audience for frightening films. Communication Research, 14(4), 415-436. doi:10.1177/ 009365087014004003

Till, B., Niederkrotenthaler, T., Herberth, A., Vitouch, P., \& Sonneck, G. (2010). Suicide in films: The impact of suicide portrayals on non-suicidal viewers' well-being and the effectiveness of censorship. Suicide \& Life-Threatening Behavior, 40(4), 319-327. doi:10.1521/suli.2010.40.4.319

Torrubia, R., Avila, C., Molto, J., \& Caseras, X. (2001). The Sensitivity to Punishment and Sensitivity to Reward
Questionnaire (SPSRQ) as a measure of Gray's anxiety and impulsivity dimensions. Personality and Individual Differences, 31(6), 837-862. doi:10.1016/S0191-8869(00)00183-5

Tóth-Király, I., Böthe, B., Tóth-Fáber, E., Gyözö, H., \& Orosz, G. (2017). Connected to TV series: Quantifying series watching engagement. Journal of Behavioral Addictions, 6, 472-489. doi:10.1556/2006.6.2017.083

Tukachinsky, R., \& Eyal, K. (2018). The psychology of marathon television viewing: Antecedents and viewer involvement. Mass Communication and Society, 21(3), 275-295. doi:10.1080/ 15205436.2017.1422765

Valkenburg, P. M., \& Peter, J. (2013). The differential susceptibility to media effects model. Journal of Communication, 63(2), 221-243. doi:10.1111/jcom.12024

Valkenburg, P. M., Peter, J., \& Walther, J. B. (2016). Media effects: Theory and research. Annual Review of Psychology, 67(1), 315-338. doi:10.1146/annurev-psych-122414-033608

van Koningsbruggen, G. M., Hartmann, T., \& Du, J. (2017). Always on? Explicating impulsive influences on media use. In P. Vorderer, D. Hefner, L. Reinecke, \& C. Klimmt (Eds.), Permanently online, permanently connected: Living and communicating in a POPC World. New York, NY: Routledge.

Vaterlaus, J. M., Spruance, L. A., Frantz, K., \& Kruger, J. S. (2018). College student television binge watching: Conceptualization, gratifications, and perceived consequences. The Social Science Journal. Advance online publication. doi:10.1016/ j.soscij.2018.10.004

Watson, D., Clark, L. A., \& Tellegen, A. (1988). Development and validation of brief measures of positive and negative affect: The PANAS scales. Journal of Personality and Social Psychology, 54(6), 1063-1070. doi:10.1037/0022-3514.54.6.1063

Whiteside, S. P., \& Lynam, D. R. (2001). The five factor model and impulsivity: Using a structural model of personality to understand impulsivity. Personality and Individual Differences, 30(4), 669-689. doi:10.1016/S0191-8869(00)00064-7

Wilbertz, T., Deserno, L., Horstmann, A., Neumann, J., Villringer, A., Heinze, H. J., Boehler, C. N., \& Schlagenhauf, F. (2014). Response inhibition and its relation to multidimensional impulsivity. Neuroimage, 103, 241-248. doi:10.1016/ j.neuroimage.2014.09.021

Wirth, W. (2006). Involvement. In J. Bryant \& P. Vorderer (Eds.), Psychology of entertainment (pp. 199-213). Hillsdale, NJ: Lawrence Erlbaum Associates.

Wirth, W., Hofer, M., \& Schramm, H. (2012). Beyond pleasure: Exploring the eudaimonic entertainment experience. Human Communication Research, 38(4), 406-428. doi:10.1111/ j.1468-2958.2012.01434.x

Wühr, P., Lange, B. P., \& Schwarz, S. (2017). Tears or fears? Comparing gender stereotypes about movies preferences to actual preferences. Frontiers in Psychology, 8, 428. doi:10.3389/fpsyg.2017.00428

Yee, N. (2007). Motivations of play in online games. CyberPsychology \& Behavior, 9(6), 772-775. doi:10.1089/cpb. 2006.9.772

Yim, O., \& Ramdeen, K. T. (2015). Hierarchical cluster analysis: Comparison of three linkage measures and application to psychological data. The Quantitative Methods for Psychology, 11(1), 8-21. doi:10.20982/tqmp.11.1.p008

YouGov Omnibus. (2017). 58\% of Americans binge-watch TV show. Retrieved from https://today.yougov.com/news/2017/ 09/13/58-americans-binge-watch-tv-shows/ 
Zillmann, D. (1988). Mood management: Using entertainment to full advantage. In L. Donohew, H. E. Sypher, \& E. T. Higgins (Eds.), Communication, social cognition, and affect (pp. 147-171). Hillsdale, NJ: Lawrence Erlbaum Associates.

Zillmann, D. (2000). Mood management in the context of selective exposure theory. In M. E. Roloff (Ed.), Communication yearbook (pp. 103-123). Thousand Oaks, CA: Sage.
Zillmann, D., \& Bryant, J. (1985). Affect, mood, and emotion as determinants of selective exposure. In D. Zillmann \& J. Bryant (Eds.), Selective exposure to communication (pp. 157-190). Hillsdale, NJ: Lawrence Erlbaum Associates.

Zuckerman, M. (1996). Sensation seeking and the taste for vicarious horror. In J. B. Weaver \& R. Tamborini (Eds.), Horror films: Current research on audience preferences and reactions (pp. 147-160). Mahwah, NJ: Lawrence Erlbaum Associates. 


\section{APPENDIX: TV SERIES-WATCHING BEHAVIORS ASSESSMENT}

How often do you generally watch at least two episodes in a row?

- Less than once a month

- Once or several times a month

- Once or several times a week

- Once or several times a day

Over the past 6 months, how much time did you generally spend watching TV series during a typical working day?

... minutes

Over the past 6 months, how much time did you generally spend watching TV series during a typical day off?

... minutes

Over the past 6 months, how many episodes did you watch during a typical screening session?

-1 episode

- 2 consecutive episodes

- 3 consecutive episodes

- 4 consecutive episodes

- 5 consecutive episodes

- 6 consecutive episodes

- More than 6 consecutive episodes
Over the past 6 months, how many TV series did you follow simultaneously?

- Only 1 series

- 2 series

- 3 series

- 4 series

-5 series

- 6 series

- More than 6 series

Do you consider yourself as dependent on TV series?

- Yes

- No

Do you consider your TV series consumption as problematic?

- Yes

- No

Do you plan to modify your pace of consumption of TV series?

- Yes

- No 